\title{
ИК-спектроскопическое исследование природных цеолитов и их лантансодержащих форм
}

\author{
Дампилова Б.В., Зонхоева Э.Л. \\ ФГБУН Геологический институт Сибирского отделения Российской академии наук, Улан-Удэ
}

Поступила в редакцию 3.10.2018 г.

DOI: https://doi.org/10.17308/sorpchrom.2019.19/648

Методом ИК-спектроскопии изучены природные образцы анальцима, мезолита, стильбита, шабазита, сколецита и их La-замещенных форм. Сорбция ионов лантана на цеолитах сопровождается частичной потерей тетраэдрического алюминия и происходит с участием структурных гидроксильных групп цеолита. Анализ ИК-спектров выявил, что сорбция ионов лантана на мономинеральных формах цеолитов вызывает снижение избыточного отрицательного заряда каркаса цеолитов в результате компенсации положительными ионами редкоземельного металла.

Ключевые слова: стильбит, анальцим, шабазит, мезолит, сколецит, лантан, ИКспектроскопия.

\section{IR-spectroscopic research of natural zeolites and their lanthanus-containing forms}

\author{
Dampilova B.V., Zonkhoeva E.L. \\ Geological Institute Siberian Branch Russian Academy of Sciences, Ulan-Ude
}

Using IR spectroscopy, natural samples of analcime, mesolite, stilbite, chabazite, scolecite and their La-substituted forms were studied. The sorption of lanthanum ions by monominerals of zeolites caused a shift in the absorption bands in the region of the characteristic deformation vibrations inside the tetrahedra in the spectra of stilbit, chabasite and mesolite. It is assumed that the shift of the absorption bands is due to the perturbation of the zeolite framework by electrostatic interactions with lanthanum ions. It was revealed that the absorption bands are shifted in the region of oscillations of the structural groups of the alumino-siliconoxygen skeleton. A rather noticeable shift of frequencies from 707 to $714 \mathrm{~cm}-1$ occurred in the region of intratetrahedral symmetric stretching vibrations in the stilbit spectrum. The shift of the absorption bands in the region of oscillations $650-820 \mathrm{~cm}-1$ indicates a partial removal of aluminum. The shift of the absorption bands in this region also occurred in the spectra of the Mesolithic, scolecite. The appearance of a new absorption band at $953 \mathrm{~cm}-1$ in the stilbite spectrum and a shift in the absorption band from $939 \mathrm{~cm}-1$ to $932 \mathrm{~cm}-1$ in the spectrum of the Mesolithic in the region of vibrations of the Al-OH bond, possibly due to the sorption of lanthanum ions with the formation of new La - bonds About with oxygen scaffold. The sorption of lanthanum ions on the mineral forms of zeolites - scolecite, analcime, mesolite, stilbite — causes a decrease in the excess negative charge of the skeleton of zeolites as a result of compensation by the positive ions of the rareearth metal. Thus, the sorption of lanthanum ions occurs at the surface centers of the zeolite, which have undergone partial dealumination, with the formation of new $\mathrm{La}-\mathrm{O}$ bonds with the oxygen of the framework. In addition, the lanthanum ion forms a bond with the oxygen of hydroxyl groups localized either in small cavities, hexagonal prisms or sodalite cells of the zeolite.

Keywords: stilbite, analcime, shabasite, mesolite, scolecite, lanthanum, IR spectroscopy. 


\section{Введение}

Метод ИК-спектроскопии предоставляет обширную информацию при изучении кристаллической структуры цеолитов, характера ассоциации молекул адсорбированной воды с обменными катионами и ионами кислорода каркаса. Для диагностики структуры цеолитов важной является область волновых чисел $330-660 \mathrm{~cm}^{-1}$, в которой проявляются деформационные колебания алюмо-кремнийкислородного каркаса. В области поглощения до $1300 \mathrm{~cm}^{-1}$ проявляются колебания структурных групп каркаса, которые подразделяются на колебания внешних связей тетраэдров и внутри отдельных тетраэдров. К колебаниям внутри тетраэдров относятся три типа: антисимметричные валентные при 1250-950 $\mathrm{cm}^{-1}$, симметричные валентные при 720$650 \mathrm{~cm}^{-1}$ и деформационные при 420-500 $\mathrm{cm}^{-1}$. Колебания внешних связей характеризуют колебания двойного кольца при 650-500 $\mathrm{cm}^{-1}$, входного окна в полости цеолита при 300-420 см-1 , симметричное валентное колебание при 750-820 см-1 и антисимметричные валентные колебания по внешним связям при 1050-1150 см${ }^{-1}[1,2]$.

Положение полос поглощения (п.п.) в области $900 \mathrm{~cm}^{-1} \mathrm{Al}-\mathrm{OH}$ - группы зависит от природы связанного с ней катиона [3]. Полосу поглощения при $945 \mathrm{~cm}^{-1}$ относят как к колебаниям решеточных алюмокислородных групп с 3-хкоординированным алюминием, так и к колебаниям связи $\mathrm{Al}-\mathrm{OH}$, возникающей при удалении атомов алюминия из решетки цеолита [1].

В спектрах цеолитов присутствует размытый континуум в области 2900-

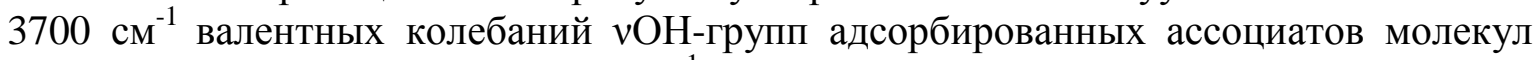
воды. Широкая полоса при $3400 \mathrm{~cm}^{-1}$ принадлежит $\mathrm{OH}^{-}$-группам, связанным водородной связью между собой и поверхностным кислородом каркаса, деформационные колебания молекул воды находятся при $1645 \mathrm{~cm}^{-1}$, на положение обеих полос оказывает влияние природа внекаркасного катиона. Узкую полосу при $3690 \mathrm{~cm}^{-1}$ приписывают колебаниям изолированных $\mathrm{OH}^{-}$-групп молекул воды, полосу поглощения $\sim 3740 \mathrm{~cm}^{-1}$ относят к поверхностным гидроксильным группам [2]. Полосы поглощения при 3540 и $3650 \mathrm{~cm}^{-1}$ отвечают структурным гидроксильным группам или бренстедовским центрам, образованным протоном и атомами кислорода каркаса цеолитов в результате гидролиза катионзамещенных форм. Высокочастотная п.п. $3640 \mathrm{~cm}^{-1}$

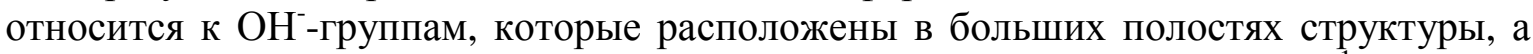
$\mathrm{OH}^{-}$- группы, которым соответствует низкочастотная полоса при $3540 \mathrm{~cm}^{-1}$, находятся в менее доступных малых полостях, гексагональных призмах или содалитовых ячейках [2-5]. Существует мнение о том, что полоса поглощения при $3520 \mathrm{~cm}^{-1}$ относится к колебаниям гидроксильных групп, непосредственно связанных с катионами [6]. В качестве льюисовских кислотных центров могут выступать также дефекты структуры цеолитов [7].

Ранее нами исследована сорбция ионов лантана на природном цеолитсодержащем туфе, основным породообразующим минералом в котором являлся клиноптилолит, изучено извлечение данным туфом ионов РЗЭ из смешанных растворов методом математического планирования эксперимента [8-10]. Цеолиты характеризуются микропористой структурой, а цеолитсодержащая порода представляет собой смесь цеолита и примесных минералов, поэтому между частицами цеолита и вмещающей породой образуются мезо- и макропоры, облегчающие взаимодиффузию обмениваемых ионов в системе сорбент - сорбат.

\section{Эксперимент}

В работе использованы мономинеральные образцы природных цеолитов шабазита, сколецита, стильбита, анальцима, мезолита, выделенных из базальтоидов 
Маргинтуйского вулканического поля [11]. La-замещенная форма мономинералов получена по методике ионного обмена в статических условиях [12] при контакте с 0.03 моль/дм ${ }^{3}$ раствором $\mathrm{LaNO}_{3} \cdot 6 \mathrm{H}_{2} \mathrm{O}$ при постоянном перемешивании на встряхивателе. Время контакта твердой и жидкой фаз составляла 24 часа, масса навески 1 г, объем раствора $50 \mathrm{~cm}^{3}$, температура $20^{\circ} \mathrm{C}$, диаметр зерен 1-2 мм.

ИК-спектры минералов цеолитов и их La-замещенных форм регистрировали на ИК-фурье-спектрометре «BRUKER IFS 25» в интервале частот 400-4000 см-1. Образцы для измерений были спрессованы в таблетки с $\mathrm{KBr}(1: 300)$ под вакуумом. Метод позволяет определить содержание веществ от 0.1 до $30 \%$.

\section{Обсуждение результатов}

Степень разрешенности характеристических полос поглощения (п.п.) в ИКспектрах минеральных форм цеолитов зависит от сложности их кристаллической структуры. Сорбция ионов лантана вызвала смещение п.п. в области характеристических деформационных колебаний внутри тетраэдров в спектре стильбита с 439 до 437, шабазита с 467 до 462, с 418 до 411, мезолита с 422 до 427 см-1 (таблица 1, 2). Сдвиг п.П. обусловлен, очевидно, возмущением каркаса цеолитов электростатическими взаимодействиями с ионами лантана. В области колебаний сдвоенных колец кристаллической структуры анальцима обнаружен сдвиг полос поглощения с 622 до $624 \mathrm{~cm}^{-1}$, связанный, очевидно, с вхождением иона лантана в поры цеолита [13].

Таблица 1. Волновые числа (см ) максимумов полос поглощения (п.п.), найденных в спектрах шабазита, анальцима, стильбита после сорбции ионов лантана

\begin{tabular}{|c|c|c|c|c|c|c|}
\hline \multicolumn{2}{|c|}{ Шабазит } & \multicolumn{2}{|c|}{ Анальцим } & \multicolumn{2}{|c|}{ Стильбит } & \multirow[b]{2}{*}{$\begin{array}{c}\text { Отнесе- } \\
\text { ние час- } \\
\text { тот }\end{array}$} \\
\hline $\begin{array}{c}\text { П.п. } \\
\text { спектра ис- } \\
\text { ходного } \\
\text { образца, } \\
\text { см }^{-1}\end{array}$ & $\begin{array}{c}\text { П. п. } \\
\text { спектра } \\
\text { образца } \\
\text { после } \\
\text { сорбции, } \\
\text { см }^{-1}\end{array}$ & $\begin{array}{c}\text { П.п. } \\
\text { спектра ис- } \\
\text { ходного } \\
\text { образца, см }\end{array}$ & $\begin{array}{c}\text { П. п. } \\
\text { спектра } \\
\text { образца } \\
\text { после } \\
\text { сорбции, } \\
\text { см}^{-1}\end{array}$ & $\begin{array}{c}\text { П.п. } \\
\text { спектра ис- } \\
\text { ходного } \\
\text { образца, см }\end{array}$ & $\begin{array}{c}\text { П. п. } \\
\text { спектра } \\
\text { образца } \\
\text { после } \\
\text { сорбции, } \\
\text { см }^{-1}\end{array}$ & \\
\hline $\begin{array}{l}418.0 \\
467.3\end{array}$ & $\begin{array}{l}410.7 * * \\
462.4^{* *}\end{array}$ & 445.7 & 446.4 & 439.1 & $437.3 * *$ & $\begin{array}{l}\delta \text { в.о. } \\
\delta \mathrm{T}-\mathrm{O}\end{array}$ \\
\hline 521.0 & 520.3 & 514.0 & 509.0 & 553.5 & 552.1 & $\begin{array}{l}\delta \mathrm{T}-\mathrm{O} \\
\text { к.с.к. }{ }^{\mathrm{x}} \\
\text { к.с.к. }{ }^{\mathrm{x}}\end{array}$ \\
\hline $\begin{array}{l}632.1 \\
707.0\end{array}$ & $\begin{array}{c}634.1^{*} \\
707.0\end{array}$ & 733.4 & 733.9 & 707.0 & 714.0* & $\begin{array}{l}v_{\mathrm{s}} \\
v_{\mathrm{s}}\end{array}$ \\
\hline & & 767.0 & 766.8 & 775.0 & 775.0 & $v_{\mathrm{s}}$ \\
\hline 1021.4 & & 1022.9 & $1027.4^{*}$ & 1021.8 & $1024.4^{*}$ & $v_{\text {as }}$ \\
\hline 1130.0 & 1025.14 & 1136.0 & $1123.0 * *$ & 1150.0 & 1150.0 & $v_{\text {as }}$ \\
\hline 1652.0 & $\begin{array}{l}1130.0 \\
1652.4\end{array}$ & 1634.2 & 1635.3 & 1651.0 & $\begin{array}{c}1649.6 \\
2305.0-\end{array}$ & $\delta\left(\mathrm{H}_{2} \mathrm{O}\right)$ \\
\hline 2855.0 & $28480 * *$ & 2855.0 & 2855.0 & 2861.0 & новая & $v(\mathrm{OH})$ \\
\hline 2916.0 & $2848.0 *$ & 2923.5 & $2930.0 *$ & 2936.0 & $2855.0 * *$ & $v(\mathrm{OH})$ \\
\hline 3270.0 & $\begin{array}{l}2923.0^{*} \\
3298.0^{*}\end{array}$ & $\begin{array}{l}3284.0 \\
3420.0\end{array}$ & $\begin{array}{c}3264.0 * * \\
3420.0\end{array}$ & 3270.0 & $\begin{array}{c}2930.0 * * \\
3270.0\end{array}$ & $v\left(\mathrm{H}_{2} \mathrm{O}\right)$ \\
\hline $\begin{array}{l}3436.9 \\
3577.0\end{array}$ & $\begin{array}{c}3447.0^{*} \\
3564.0^{*} *\end{array}$ & $\begin{array}{l}3564.0 \\
3625.0 \\
\end{array}$ & $\begin{array}{l}3557.0^{* * *} \\
3617.2^{* * *}\end{array}$ & $\begin{array}{l}3441.0 \\
3563.1 \\
3604.0\end{array}$ & $\begin{array}{l}3441.0 \\
3563.1 \\
\end{array}$ & $\begin{array}{l}\text { B.c.OH } \\
\mathrm{O}(3) \mathrm{H} \\
\mathrm{O}(1) \mathrm{H}\end{array}$ \\
\hline
\end{tabular}

Примечание: * - увеличение полосы, ** - уменьшение полосы, к.с.к ${ }^{\text {x. }}$ - колебания сдвоенных колец 
Таблица 2. Волновые числа (см) максимумов полос поглощения (п.п.), найденных в спектрах мезолита, сколецита после сорбции ионов лантана

\begin{tabular}{|c|c|c|c|c|}
\hline \multicolumn{2}{|c|}{ Мезолит } & \multicolumn{2}{|c|}{ Сколецит } & \multirow[b]{2}{*}{ Отнесение частот } \\
\hline $\begin{array}{c}\text { П.п. } \\
\text { спектра исход- } \\
\text { ного } \\
\text { образца, } \\
\text { см }^{-1}\end{array}$ & $\begin{array}{c}\text { П. п. } \\
\text { спектра об- } \\
\text { разца после } \\
\text { сорбции, см }\end{array}$ & $\begin{array}{c}\text { П.п. } \\
\text { спектра исходно- } \\
\text { го } \\
\text { образца, см }{ }^{-1}\end{array}$ & $\begin{array}{c}\text { П. п. } \\
\text { спектра об- } \\
\text { разца после } \\
\text { сорбции, см }\end{array}$ & \\
\hline 422.1 & $426.6^{*}$ & $\begin{array}{l}426.3 \\
494.9\end{array}$ & $\begin{array}{l}427.2 \\
495.5\end{array}$ & $\begin{array}{l}\delta \text { в.о. } \\
\delta \text { T-O }\end{array}$ \\
\hline 502.0 & $505.0 *$ & & & \\
\hline 537.0 & 537.0 & & 628.8 & к.с.к. ${ }^{\mathrm{x}}$ \\
\hline 629.6 & 628.2 & 021.3 & $692.1^{*}$ & $v_{\mathrm{s}}$ \\
\hline 691.0 & $687.0 * *$ & $68 / .0$ & 720.3 & $v_{\mathrm{s}}$ \\
\hline 714.0 & 714.0 & 114.0 & 931.3 & $v_{\mathrm{s}}$ \\
\hline 939.0 & $932.0^{* *}$ & 932.0 & 952.7-новая & \\
\hline 983.1 & 984.2 & $\begin{array}{c}987.0 \\
1014.0\end{array}$ & $\begin{array}{c}988.0 \\
1020.9^{*} \\
11016^{*}\end{array}$ & $\begin{array}{l}v_{\text {as }} \\
v_{\text {as }} \\
y_{\text {in }}\end{array}$ \\
\hline 1096.0 & 1096.0 & 1096.0 & & \\
\hline 1423.0 & $1419.5^{* *}$ & 1593.0 & $1590.8 * *$ & \\
\hline $\begin{array}{l}1650.0 \\
1662.4\end{array}$ & $\begin{array}{l}1650.0 \\
1661.0\end{array}$ & $\begin{array}{l}1595.0 \\
1649.1 \\
1664.4\end{array}$ & $\begin{array}{c}1648.7 \\
1664.7 \\
2295.0-\text {-новая }\end{array}$ & $\begin{array}{l}\delta\left(\mathrm{H}_{2} \mathrm{O}\right) \\
\delta\left(\mathrm{H}_{2} \mathrm{O}\right)\end{array}$ \\
\hline $\begin{array}{l}2861.0 \\
2923.0\end{array}$ & $\begin{array}{l}2855.0^{* *} \\
2930.0^{*}\end{array}$ & $\begin{array}{l}2861.0 \\
2930.0 \\
3059.0\end{array}$ & $\begin{array}{c}2855.0 * * \\
2930.0 \\
3073.0^{*} \\
3231.5\end{array}$ & $\begin{array}{l}v(\mathrm{OH}) \\
v(\mathrm{OH}) \\
v(\mathrm{OH}) \\
v\left(\mathrm{H}_{2} \mathrm{O}\right)\end{array}$ \\
\hline 3223.0 & $3243.0^{*}$ & 3231.6 & $\begin{array}{c}3231.5 \\
3327.2 * *\end{array}$ & $\begin{array}{l}v\left(\mathrm{H}_{2} \mathrm{O}\right) \\
v\left(\mathrm{H}_{2} \mathrm{O}\right)\end{array}$ \\
\hline 3277.0 & $3284.0 *$ & $\begin{array}{l}3332.0 \\
34077\end{array}$ & 3408.9 & $v\left(\mathrm{H}_{2} \mathrm{O}\right)$ \\
\hline 3399.7 & 3398.4 & $\begin{array}{l}340 \% .7 \\
3509.0\end{array}$ & $3506.7 * *$ & $v_{s}+\omega$ \\
\hline 3535.9 & $3537.5^{*}$ & 3591.0 & $\begin{array}{c}3585.1 * * \text {-из } 2 \\
\text { стала одна }\end{array}$ & $\mathrm{O}(3) \mathrm{H}$ \\
\hline
\end{tabular}

Примечание: * - увеличение полосы, ** - уменьшение полосы, к.с.к ${ }^{\text {x. }}$ - колебания сдвоенных колец

Достаточно заметное смещение частот с 707 до $714 \mathrm{~cm}^{-1}$ произошло в области внутритетраэдрических симметричных валентных колебаний в спектре стильбита (табл. 1). Как известно, полоса поглощения в области 650-820 cм${ }^{-1}$ зависит от силикатного модуля в каркасе цеолита: частичное удаление алюминия приводит к смещению полос поглощения $[2,6]$. Поэтому отмеченный факт служит, вероятно, свидетельством частичного деалюминирования стильбита. Смещение полос поглощения в данной области произошло также в спектрах мезолита с 691 до $687 \mathrm{~cm}^{-1}$; сколецита с 687 до 692, с 714 до $720 \mathrm{~cm}^{-1}$ (табл. 2). Процесс деалюминирования достаточно сложен в связи с разрывом связей $\mathrm{Si}-\mathrm{O}-\mathrm{Al}$ и замещением каркасного алюминия на гидроксильные группы [12]. В результате реакции гидроксильная форма цеолита переходит в деалюминированную форму.

$$
\left[(\mathrm{AlOOH})_{\mathrm{x}}\left(\mathrm{SiO}_{2}\right)_{\mathrm{n}-2}\right]^{0}+3 \mathrm{xH} \leftrightarrows\left[\left(\mathrm{H}_{4} \mathrm{O}_{2}\right)_{\mathrm{x}}\left(\mathrm{SiO}_{2}\right)_{\mathrm{n}-\mathrm{x}}\right]^{0}+\mathrm{xAl}^{3+}
$$

$\mathrm{B}$ спектре сколецита наблюдается появление новой полосы поглощения при $953 \mathrm{~cm}^{-1}$. Поскольку в этой области проявляются колебания связи $\mathrm{Al}-\mathrm{OH}$, то можно сделать вывод о том, что ионы лантана сорбируются на этих центрах с образованием 
новых связей La - O [3, 14]. В спектрах мезолита наблюдается смещение п. п. $939 \mathrm{~cm}^{-1}$ до $932 \mathrm{~cm}^{-1}$.

Сорбция ионов лантана сопровождается снижением избыточного отрицательного заряда каркаса (ИОЗК), т.е. ионности каркасных связей Т-О, о чем можно судить по общему высокочастотному смещению полос поглощения, в особенности, в области антисимметричных валентных колебаний $\mathrm{TO}_{4}$ [15]. Предполагается, что смещение полос, наблюдаемое в спектрах сколецита с 1014 до 1021, стильбита с 1022 до 1024, анальцима с 1023 до 1027, шабазита с 1021 до 1024 (см ${ }^{-1}$ ) (табл. 1), происходит в результате образования донорно-акцепторной связи между свободными d-орбиталями лантана и не поделённой электронной парой атомов кислорода, расположенных на поверхности цеолита [14]. В области антисимметричных валентных колебаний по внешним связям $\left(1050-1150 \mathrm{~cm}^{-1}\right)$ произошли сдвиги частот в спектрах сколецита с 1096 до $1102 \mathrm{~cm}^{-1}$ и анальцима с 1136 до $1123 \mathrm{~cm}^{-1}$.

Спектры анальцима, стильбита и шабазита характеризуются одной сильной п.п. деформационных колебаний молекул воды, соответственно 1634, 1651,1652 cм-1. В спектрах узкопористых волокнистых цеолитов, к которым относятся исследуемые минералы - сколецит, мезолит, наблюдается более тонкая структура вследствие сильного взаимодействия катиона с молекулами воды [2]. Так, в спектре сколецита, кроме узких п.п. деформационных колебаний воды при 1649 и 1664 см$^{-1}$, имеется п.п. $1593 \mathrm{~cm}^{-1}$, которая смещается в низкочастотную область до $1591 \mathrm{~cm}^{-1}$ под влиянием ионов лантана.

Полоса поглощения при $3540 \mathrm{~cm}^{-1}$, отвечающая колебаниям структурных ОНгрупп в малых полостях, гексагональных призмах или содалитовых ячейках, исчезает в спектре La-формы стильбита, что позволяет сделать заключение об образовании связи La - O в указанных местах локализации. B спектре La-формы анальцима п.п. при $3564 \mathrm{~cm}^{-1}$ становится интенсивнее и смещается до $3557 \mathrm{~cm}^{-1}$; La- формы шабазита с 3577 до $3564 \mathrm{~cm}^{-1}$ в результате возможного ослабления гидроксильных связей. Возможно, ионы лантана сорбируются в виде аквокомплекса.

$$
\begin{aligned}
& -\mathrm{Al}-\mathrm{O} \underset{\downarrow}{-} \mathrm{Si}-\mathrm{O}-\stackrel{\mathrm{Al}}{\downarrow}- \\
& \mathrm{La}-\left(\mathrm{OH}^{2+} \sim \mathrm{H}\right) \quad \mathrm{H} \sim \mathrm{O} \sim \mathrm{La}^{2+} \\
& \mathrm{H}_{2} \mathrm{O}
\end{aligned}
$$

Спектр сколецита содержит семь п.п. в области валентных колебаний воды $3591,3535,3509,3408,3332,3232$ и $3059 \mathrm{~cm}^{-1}$, из которых наиболее сильные 3535 , 3408, 3332, 3232 см$^{-1}$ вызваны основными колебаниями асимметричной молекулы. Слабые п.п. являются комбинационными частотами типа $v_{s}+w$, где $v_{s}$ - частота валентного колебания ОН- связи воды, $w$ - частота колебания решетки каркаса. В спектре La-формы сколецита наблюдается сдвиг п.п. до 3585, 3507, 3409, 3327, 3231, $3073 \mathrm{~cm}^{-1}$ и увеличение их интенсивности, свидетельствующей об изменении распределения заряда внутри молекулы воды, происшедшего в результате образования более полярной связи La - OH. Полоса поглощения при $3650 \mathrm{~cm}^{-1}$ структурных гид-

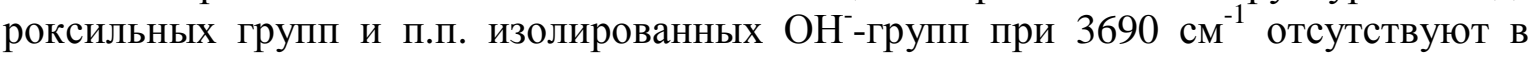
спектрах исходных образцов.

\section{Заключение}

Анализ ИК-спектров выявил, что сорбция ионов лантана на минеральных формах цеолитов - сколеците, анальциме, мезолите, стильбите вызывает снижение 
избыточного отрицательного заряда каркаса цеолитов в результате компенсации положительными ионами редкоземельного металла. Сорбция ионов лантана происходит на поверхностных центрах цеолита, подвергшихся частичному деалюминированию, с образованием новых связей $\mathrm{La}-\mathrm{O}$ с кислородом каркаса. Кроме того, ион лантана образует связь с кислородом гидроксильных групп, локализующихся либо в малых полостях, гексагональных призмах или содалитовых ячейках цеолита.

\section{Работа выполнена при финансовой поддержке ФАНО проект № 0340-2016-0006 и гранта РФФИ 16-05-01041_a.}

\section{Список литературы}

1. Цицишвили Г.В. Природные сорбенты. М. Наука. 1967. С. 45-56.

2. Брек Д. Цеолитовые молекулярные сита. М. Мир. 1976.781 с.

3. Болдырев А.И. Инфракрасные спектры минералов. М. Недра. 1976. 199 с.

4. Горохов В.К. Цеолиты Сахалина. Владивосток. Дальневост. кн. изд-во. 1982. 108 c.

5. Трохимец А.И. // Журнал физической химии. 1997. Т. 71. № 11. С. 2013.

6. Химия цеолитов и катализ на цеолитах / Под ред. Дж. Рабо. Т.1. М. Мир. 1980. 506 c.

7. Ульянова Н.Ю. Дисс. канд. хим. наук. Санкт-Петербург. 2016. 139 с.

8. Дампилова Б.В., Зонхоева Э.Л. // Журнал физической химии. 2013. Т. 87. № 8. С. 1361-1366

9. Дампилова Б.В., Зонхоева Э.Л. // Сорбиионные и хроматографические проuеccbl. 2012. T. 12. № 3. С. 439-444

\section{References}

1. Cicishvili G.V. Prirodnye sorbenty. M., Nauka, 1967, pp. 45-56.

2. Brek D. Ceolitovye molekulyarnye sita. M., Mir, 1976, 781 p.

3. Boldyrev A.I. Infrakrasnye spektry mineralov. M., Nedra, 1976, 199 p.

4. Gorohov V.K. Ceolity Sahalina. Vladivostok, Dal'nevost. kn. izd-vo, 1982, 108 p.

5. Trohimec A.I., ZHurnal fizicheskoj himii, 1997, Vol. 71, No 11, pp. 2013.

6. Himiya ceolitov i kataliz na ceolitah / Pod red. Dzh. Rabo. T.1. M., Mir, 1980, 506 p.

7. Ul'yanova N.Yu. Diss. kand. him. nauk. Sankt-Peterburg, 2016, 139 p.

8. Dampilova B.V., Zonhoeva EH.L., ZHurnal fizicheskoj himii, 2013, Vol. 87, No 8, pp. 1361-1366.
10. Зонхоева Э.Л., Дампилова Б.В. // Сорбиионные и хроматографические проиессы. 2017. Т. 17. № 5 С. 916-922.

11. Цеолитоносность базальтов Забайкалья / Под ред. Андреева Г.В. Новосибирск. Наука. сиб. Отд-ние. 1989. 96 с.

12. Челищев Н.Ф., Володин В.Ф., Крюков В.Л. Ионообменные свойства природных высококремнистых цеолитов. М. Наука. 1988. $128 \mathrm{c}$.

13. Ракитская Т.Л. // Вісник ОНУ. Хімія. 2015. Т. 20. Вип. 2(54). С. 6-15. Режим доступа: $\quad$ http://dx.doi.org/10.18524/23040947.2015.2(54).50624

14. Макаров А.В. Дисс. Канд. Техн. наук. Томск, 2013.17 c.

15. Кошелева Л.С. // Известия Академии наук. Серия химическая. 1994. № 3. С. 387391

9. Dampilova B.V., Zonhoeva EH.L., Sorbcionnye i khromatograficheskie protsessy, 2012. 2012, Vol. 12, No 3, pp. 439-444.

10.Zonhoeva EH.L., Dampilova B.V., Sorbcionnye i khromatograficheskie protsessy, 2017, Vol. 17, No 5, pp. 916 -922.

11.Ceolitonosnost' bazal'tov Zabajkal'ya / Pod red. Andreeva G.V. Novosibirsk, Nauka, sib. Otd-nie, 1989, 96 p.

12.CHelishchev N.F., Volodin V.F., Kryukov V.L. Ionoobmennye svojstva prirodnyh vysokokremnistyh ceolitov. M., Nauka, 1988, 128 p.

13. Rakitskaya T.L., Visnik ONU. Khimiya, 2015, Vol. 20, No 2 (54). pp. 6-15. Rezhim dostupa: http://dx.doi.org/10.18524/23040947.2015.2(54).50624 
14.Makarov A.V. Diss. Kand. Tekhn. nauk. Tomsk, $2013.17 \mathrm{p}$.

Дампилова Баярма Викторовна - к.Х.н., н. с., лаборатория гидрогеологии и геоэкологии ФБГУН Геологического института СО РАН, Улан-Удэ

Зонхоева Эльвира Лопсондоржиевна к.х.н., в.н.с., лаборатория гидрогеологии и геоэкологии ФБГУН Геологического института СО РАН, Улан-Удэ
15.Kosheleva L.S., Izvestiya Akademii nauk. Seriya khimicheskaya, 1994, No 3, pp. 387-391.

Dampilova Bayarma V. - Ph.D (Chem), researcher, Geological Institute Siberian Branch Russian Academy of Sciences, Ulan-Ude, bdampilova@geo.stbur.ru

Zonkhoeva Elvira L. - Ph.D (Chem), leading researcher, Geological Institute Siberian Branch Russian Academy of Sciences, Ulan-Ude, zonhoevae@geo.stbur.ru 